\title{
Increasing Metacognitive Awareness through Reflective Writing: Optimizing Learning in Engineering
}

\section{Dr. Patti Wojahn, New Mexico State University}

As past Writing Program Administrator and current Interdisciplinary Studies Department Head, I have worked closely with academic departments interested in supporting the writing, communication, and academic abilities of students. For many years, I worked with Integrated Learning Communities for at-risk, entry-level engineering majors, overseeing development and use of a curriculum adapted specifically for this group. I continue to analyze data from research studies exploring challenges and identifying atrisk characteristics among students in first-year writing courses. I also worked on an initiative focused on writing in the disciplines as part of our university's Higher Learning Commission 10-year re-accreditation cycle. As Borderlands Writing Project Director, I have worked with K-16 teachers to strengthen quality in using writing in their courses to help students learn, regardless of discipline.

\section{Mr. Germain Degardin, Southwest Outreach Academic Research (SOAR) Center}

Germain graduated from New Mexico State University with a Bachelor in Economics, a Master in Business and Administration, a Master in Curriculum and Instruction, and a secondary education teaching license. Germain currently works for the Southwest Outreach Academic Research (SOAR) Center as Senior Project Specialist evaluating and assessing the impact of educational outreach programs and other education-related projects.

\section{Muhammad Dawood}

Dr. Muhammad Dawood received his BE degree from the NED University of Engineering and Technology, Karachi, Pakistan, 1985, and his MS and Ph.D. degrees, the University of Nebraska-Lincoln, in 1998 and 2001, respectively, both in electrical engineering. Dr. Dawood is involved in teaching both nationally and internationally since 1995. At present, Dr. Dawood is an Associate Professor at the Klipsch School of Electrical and Computer Engineering, New Mexico State University (NMSU), Las Cruces, New Mexico. Dr. Dawood's research interests lie in the area of Engineering Education, EM Propagation through Dispersive media; radar; and Antennas; He is a member of IEEE.

\section{Dr. Melissa J. Guynn, New Mexico State University}

I am a cognitive psychologist with a primary interest in human memory.

\section{Dr. Rachel Boren, New Mexico State University}

Dr. Rachel Boren is the Director of the SOAR Evaluation and Policy Center in the College of Education at New Mexico State University. Her expertise is in research methodology and program evaluation in the social sciences. 


\title{
Increasing Metacognitive Awareness through Reflective Writing: Optimizing Learning in Engineering
}

\author{
Dr. Patti Wojahn, New Mexico State University \\ Germain Degardin, New Mexico State University \\ Muhammad Dawood, New Mexico State University \\ Melissa Guynn, New Mexico State University \\ Rachel Boren, New Mexico State University
}

\section{Introduction}

Engineering programs often struggle to optimally support and retain promising students. To attempt to address that issue at a Southwest HSI land-grant university, our interdisciplinary team of researchers set out to study the impacts of putting learning and success more directly into the hands of students. We began exploring what we could learn from preparing first-year engineering students to take more control of and responsibility for their learning and their growth as learners [1]. With faculty and graduate students from engineering, education, psychology, as well as rhetoric and professional communication programs, we tapped our diverse backgrounds and research literature to create materials and opportunities to help students think about if not improve their own learning.

In this article, we report on preliminary analyses of several aspects of our three-year study investigating the effects of first-year students' metacognitive awareness of learning on academic performance in a college engineering program. Specifically, we focus on information that students reported in reflective writings on their past and current studying strategies and how we see their growth in metacognitive awareness as reflected in responses to journal prompts about their study practices and class performance.

Throughout our 3-year NSF-supported research grant, we have introduced students to the significance and the potential of metacognitive awareness, defined as the "active monitoring," regulating, and orchestrating of activities "in service of some concrete goal or objective" [2]. In 2016 and 2017, we opted for splitting the first-year engineering students' cohort into two groups, one control and one experimental, so we could note any effects of our interventions. While students' grades were not found to vary in statistically significant ways (outside of the exam results just after our intervention in Fall 2017, where experimental students performed significantly better), we did see an uptake in the way the experimental students discussed their metacognitive understandings of their own study strategies and practices. Their reflections on their learning and intentional approaches gave us hope that our interventions were "taking." With our beliefs in the value of attention to metacognition as well as a noted increase in awareness of effective study strategies, we included all students in our Fall 2018 interventions. The interventions included:

- A researcher-led in-class workshop on metacognition based on work by leaders in this area 
- Easy-to-use reference materials to serve as reminders of information they were exposed to in the metacognition workshop

- Students' reflective writings throughout the semester in response to metacognitive journal prompts about their learning approaches, study practices, and course performances

Our aims included exploring whether our materials and journal prompts could help increase metacognitive awareness and, if so, to lead students to alter their study practices or thoughts about learning, thereby ideally improving their performance if not retention [3], [4]. To measure the impact, if any, of our interventions, we distributed two surveys, one on metacognitive awareness, the other on study practices at both the beginning of the semester and at the end. In this article, however, we focus on what we learned from the reflective intervention - the journal prompts asking students to consider if not work to improve their study practices and effects. After sharing highlights from relevant research that informed our study, particularly with respect to metacognition and reflection as well as student outlooks and attitudes toward learning, we present findings on and discussion of Fall 2018 students' development of studying behaviors related to our interventions.

When learners take time to think about what they are doing and how-and with what effects - it is possible for them to marshal that information to enhance both existing strengths and weaknesses [5], for instance, by seeking alternative approaches to learning. With so much attention to content in many fields, we often risk neglecting to help students to process, understand, and learn course material, particularly in our entry-level courses such as the engineering seminar we focused on. Our interventions are meant to raise students' awareness of how they, not just grades or feedback from instructors, can themselves assess their learning and ideally make informed decisions on how to proceed and learn. Reflection and reflective writing have long been valued as paths in support of such learning. Such reflective writing can help learners not just understand important concepts but engage in thinking about and learning such concepts [6], [7]. As explained below, as we analyzed data from the journal responses prompting reflection, we saw an increase in students' range of study strategies as well as in their use of study practices that research indicates to be more likely to support learning (i.e., habits invoking "deep processing" such as relating new information to existing knowledge, according to) and a decrease in those less effective practices being reported (surface-level learning such as rote memorizing) [8].

\section{Data Collection}

Students enrolled in the first-year engineering seminar were given two surveys at the beginning and at the end of the semester. The first was a Metacognitive Awareness Inventory [9] that we had condensed and modified based both on results from our study's initial two years as well as on information from [10] on strategies to promote metacognition (such as having students consider the instructor's goals for an assignment). This survey asked students to rate the extent to which they agreed with statements related to thinking about learning, such as "After I have tried to answer a question or solve a problem, I ask myself if I have considered all possible answers or solutions" and other statements related to what they think or do before, during, and after studying or completing homework or exams and how they assess their approaches. The second survey focused more on study practices, asking students to rate the extent to which they applied specific 
study strategies such as "I practice explaining the course material to others" or "I start doing homework too late." Such statements were largely based on those from [11] on teaching students to learn.

Assigned prior to the first exam, the first set of journal prompts asked students to reflect on and write about aspects related to high school practices, such as how long they tended to study per week in high school; strategies they used for studying and learning; the best learning strategy that had worked for them. We then asked them to report on how they were preparing for their first engineering college exam; to share how confident they felt about performing well on this exam, and to explain their reported level of confidence.

The next set of journal prompts, assigned prior to the second exam, asked questions about what students do when they are stuck or struggling in understanding a concept, formula, or idea; how they were preparing for their upcoming exam; and how they tend to recover or "bounce back" when they haven't performed as well as they had wished. The final set of prompts asked students to address whether they were satisfied with their scores on the second exam and to list strategies they had used to prepare for the exam that they considered "effective." As in Journal 2, we asked which specific strategies they employ when not comprehending a concept or idea and which specific strategies they planned to draw on for preparing for the third exam. In addition, students were asked to explain how, if at all, they had applied what they learned from our interventions (the class workshop and materials on metacognitive and study skill practice), and to explain their answers. Finally, students were asked to list strategies that they had learned from our interventions that they intended on using in future semesters. Responses to journal prompts were collected, prepared for analysis through the qualitative software MAXQDA, and then coded by pairs of researchers into patterns or themes. Each journal prompt was completed and turned in the week before the exam, with exams occurring late September, October, and November.

Finally, in addition to demographic information, we collected student performance data on course exams, data that is currently being analyzed as we further analyze the reflective journals.

\section{Preliminary Findings}

Time Spent Studying. We generally believe that how students study can be more impactful than the time actually spent studying. Nonetheless, at the start of the semester, we asked students to report their weekly average studying times in high school to get a comparative sense of the amount of time they spent later in the semester and after our initial workshop interventions.

Not surprisingly, we learned that students overall reported devoting more time studying in college (in fact, the time they reported studying for their first-year engineering seminar alone was not so different from the time they had reported studying for all high school classes put together). When asked about time spent studying outside of class in high school, most students (80\%) reported spending 4 or fewer hours (see Fig. 1). While 15\% reported approximately 6 hours, $5 \%$ of students reported spending 8 hours or more studying weekly in high school. We see 
these results as supporting the need for our work in helping students, especially those with little practice studying, to "learn how to learn" by reflecting on their own practices and performances.

Figure 1. Amount of Time Students Reported Studying Weekly Outside of Class in High School $\left(\mathrm{n}=323\right.$; Week 3 of $1^{\text {st }}$ Semester).

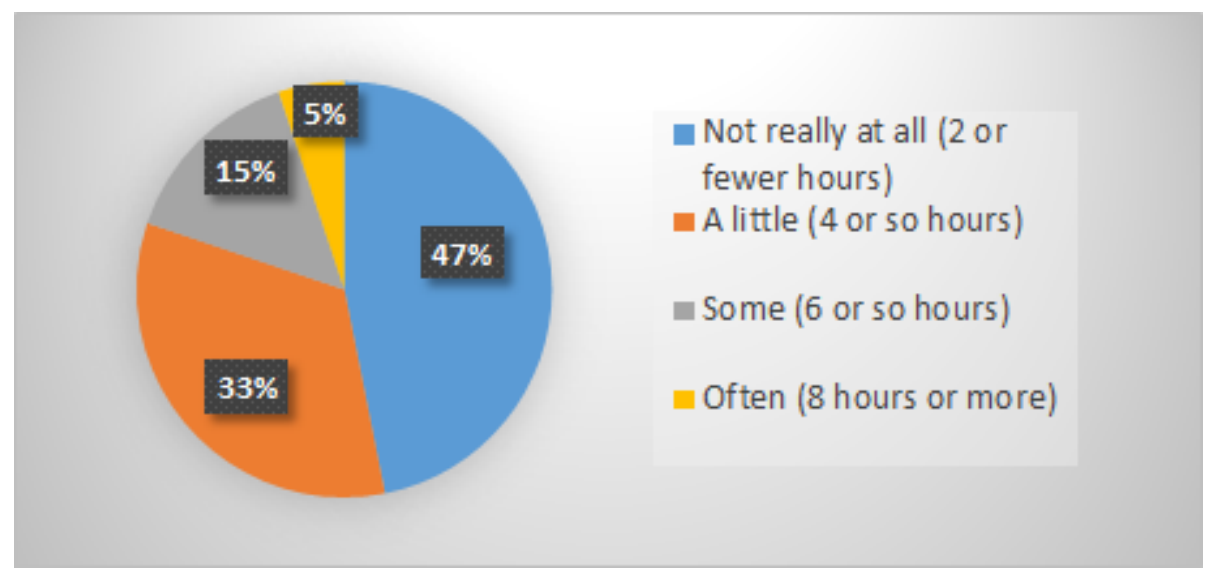

In the second journal, we asked students to select average weekly time spent studying based on four specific time options. Students' reported study time averages went up, with the most common response (at $42 \%$ ) being 4-8 hours on average per week (see Fig. 2).

Figure 2. Amount of Time Students Reported Studying Weekly Outside of Class in College $(\mathrm{n}=284)$; Week 7 of $1^{\text {st }}$ Semester $)$.

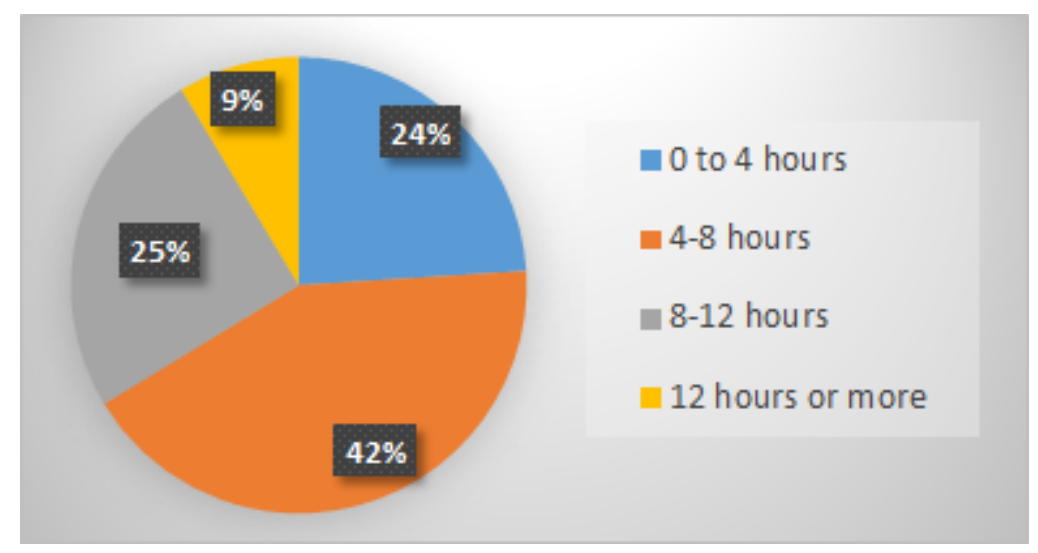

As displayed in Table 1, whereas $80 \%$ of students reported 4 or fewer hours of weekly study times for high school, just $24 \%$ reported that small amount as they approached their second engineering exam. Moreover, with just $5 \%$ of students reporting average weekly study times of 8 hours or more in high school, $34 \%$ reported average weekly study times of 8 or more hours as they approached their second exam.

Table 1. Weekly Average Study Time Reported for High School vs. College. 


\begin{tabular}{|l|c|c|}
\hline Hours & High School & Mid-First College Semester \\
\hline 4 or fewer & $80 \%$ & $24 \%$ \\
\hline More than 4, fewer than 8 & $15 \%$ & $42 \%$ \\
\hline $\mathbf{8}$ or more & $5 \%$ & $34 \%$ \\
\hline
\end{tabular}

We cannot attribute the reported increase in study time in comparison to reported times mentioned for high school directly to our intervention, but we trust that our metacognitive and study strategy workshop made students aware of the importance of engaging to learn as well as of being reflective about their approaches to studying, all of which was confirmed to an extent in our final journal prompt.

Although it was clear students overall reported spending more time studying in college as opposed to high school, findings from [12] concluded that full-time engineering seniors tend to spend on average 19 hours preparing for classes on a weekly basis, including projects and laboratory work. We do not expect first-year, first-semester engineering students to match reported study time of engineering seniors, but we believe it could be useful to let them know what to expect as they enter upper-division courses in engineering or other disciplines.

Now that we shared differences in students' reported study times in high school as opposed to college, we next report on differences in reported study behaviors in high school and in their $1^{\text {st }}$ college semester.

Study Strategies. A key message of our effort was that the amount of time one spends studying is not necessarily as important as how one spends that time studying. More than a month after our intervention workshop as well as at the end of the semester, we noted substantive changes in students' reported study practices when compared to those they reported at the beginning of the semester.

When asked what strategies they used when studying in high school, students listed a range of practices, but in Journal 1, most of the comments ( $62 \%$ of the 483 comments from 323 students) mentioned the basic and potentially ineffective strategy of reviewing material, including notes, course materials, assigned readings, homework, and quizzes [13]. The most common review strategy (mentioned by $31 \%$ of students) was the reviewing of "notes," a finding that can be viewed as problematic for a number of reasons. In taking notes, students may not attend to the most critical information; their understanding of the material they are taking notes on may also not be accurate. Reviewing notes as the most consistent approach to learning might lead to missing important information all together or reinforcing any misunderstandings reflected in their notes. Also of concern, more than one in $10(13 \%)$ students mentioned the approach of "cramming," and nearly one in $10(9 \%)$ reported in response to this question that they did not study in high school.

Our findings do indicate that some students reported employing study strategies with more likelihood to lead to learning. For instance, $18 \%$ of students reported working on practice problems, an approach that can be particularly valuable for learning in engineering and STEM courses [13], [14]. Another strategy, rewriting one's notes, a practice reported by $11 \%$ of students, could also prove valuable but poses the same risks mentioned above that come with 
relying on one's notes; nonetheless, we see rewriting notes as a more active and perhaps more impactful practice than merely reviewing notes [15]. Studying with a partner was a third practice we see as promising, but studying with a partner was reported by just $6 \%$ of students.

Interestingly, when asked to share the strategy that had proven most effective for them in high school, the most common response was that completing practice problems (or similarly redoing homework problems) proved most effective. In other words, although it seems a good share of students is aware of the value of this practice, students reported being far more likely to rely on the potentially less promising practice of reviewing notes.

In the end, most strategies that students reported employing in high school would correspond to study strategies not necessarily leading readily to optimal learning. This result suggests a need for approaches such as our interventions, designed to make students aware (or reminded) of (1) study strategies more likely to foster learning and (2) metacognitive approaches prompting more reflective and intentional "learning to learn."

In contrast to results on reports of study practices in high school, when asked near the end of the semester, weeks after our metacognition and study strategies workshop, how they planned to study or were studying for their third exam, far fewer students- $40 \%$ in contrast to $62 \%$ at the beginning - reported that they would use the strategy of reviewing. While this statistic suggests that a number of students changed or added study practices, reviewing still proved at the end of the semester as the most common "go-to" strategy. However, what they said they were focused on during the practice of review changed, with just $12 \%$ of those who reported they would use or were using reviewing specifically mentioning reviewing their own notes, in contrast to $31 \%$ of students listing this as a primary strategy at the beginning of the semester. Reviewing materials tends to have a long history in the life of a student, and it is not necessarily a negative [3], [13]. We see adding a wider range of approaches to their study strategy repertoire, beyond the practice of review, as potentially valuable.

In contrast, whereas $18 \%$ of students at the beginning of the semester reported working practice problems or reworking prior problems as a strategy they had typically used to prepare for an exam in high school, at the end of the semester $29 \%$ mentioned practicing problems as an approach they were planning to use or were already using to prepare for the third exam in their first-year college engineering course. The strategy of doing sample or practice problems as a step toward learning has been found to be particularly valuable in STEM courses such as engineering [13].

Education research also lists study groups or partners as a recommended strategy for learning [3]. At the semester's beginning, $6 \%$ of students mentioned invoking this practice, whereas at the end of the semester, $16 \%$ of students mentioned they were using or planning to use study groups to prepare for their third exam. We also were somewhat encouraged to see that in preparing for their third exam, more than 1 in 10 students (12\%) listed review sessions as a resource they would draw from to learn in preparation for their exam. Given that the engineering seminar offers these sessions to help students prepare for exams, we would expect to see this percentage to be higher. 
Time management, another strategy emphasized in our intervention workshop and materials, was also listed as an approach that $12 \%$ of students specifically reported they planned to take into account or were already using as they prepared for their third exam. Interestingly, no students at the outset of the semester mentioned the metacognitive strategy of considering how they would use their time in preparation for exams. At the end of the semester, however, students listed such strategies as studying more frequently but in shorter sessions, breaking up their study sessions with other activities, or preparing in smaller increments.

Effective time management, in fact, was listed as the most popular metacognitive approach students reported they gained from our intervention, the strategy that about $25 \%$ said they would continue to employ in future semesters. Sub-strategies related to this approach included:

- studying in smaller increments as opposed to lengthy sessions

- determining how to organize/optimize the time they had for studying

- increasing the amount of time devoted to focused studying

- attending to taking breaks from studying

- avoiding cramming

When asked if they adjusted the way they study as a result of our interventions, $58 \%$ of students said they had. Among these students, when asked to describe how they had changed their study practices, 39\% stated that they had improved their time management (including studying more efficiently and intentionally scheduling or planning their use of study time). In addition, 36\% stated that they had developed or practiced more effective study strategies, such as reading more purposefully, focusing on key ideas in taking better notes or asking for help (a practice students hadn't mentioned applying at all in high school). Finally, 19\% mentioned that they would mentally adjust their approaches to learning, a real aim of metacognitive approaches to learning. Among these, students mentioned identifying and focusing more on key material, being more aware of the need for studying and increasing their motivation or confidence, the latter topics which we will take up in subsequent analyses.

\section{Conclusions and Implications}

One purpose of our study was to try to improve metacognitive awareness and enhance students' approaches to studying. Although exam grades showed mitigated results, we observed interesting changes in students' reported studying strategies and learning mindsets. We also observed how reflective writing can serve not only as a window into students' metacognitive awareness (and more) but also as a valuable means for students themselves to contemplate if not learn from connections, if any, between their study strategies and learning as well as performance.

To review some key findings from our first pass through the data, we observed a shift in the number of hours students reported having studied in high school to time reportedly spent studying near the end of their first college semester. Comparing the data collected within the first weeks of the fall semester and the mid- and end-of-semester data, we noted many students developing a better sense of what strategies they use and why. Importantly, we also observed an increased level of engagement in higher-level study strategies along with improved levels of metacognitive awareness. For instance, compared to at the start of the semester, at the semester's end, many students mentioned employing a much wider range of recommended strategies, 
including studying in groups, completing relevant practice problems, intentionally managing study time to focus on critical information, and seeking help when they did not understand something.

These preliminary results reinforce to us that our study, designed to introduce students to metacognitive approaches to learning through minimally intrusive interventions taking little time, brought promising results for the learners and their approaches to studying and learning. Specifically, our conclusions about our interventions are as follows:

- Minimal introductions to and prompting toward metacognitive awareness and effective study skill practices, such as our one-hour workshop coupled with materials for future use, can support students' in expanding their study strategy repertoire in more reflective and intentional ways.

- Even brief reflective writings allowing for students to consider elements of their study practices, their strengths and weaknesses as learners, their study and performance aims, and more can instantiate valuable approaches to learning such as identifying what is working and what is not [1].

- Solely emphasizing content in our courses risks opportunities to help students "learn to learn" that material.

The study shows promise for instructors across all disciplines interested in improving students' learning practices and approaches to thinking about learning and performance with minimal interventions. Based on our review of students' reflective journals, we conclude with 'takehome" notions that call for us to take time to foster metacognitive awareness, particularly with respect to reflective writing and thinking [16], [17]:

- Learning in college courses requires time (e.g., senior engineering majors have been found to spend an average of 19 hours weekly studying), but merely spending more time studying will not likely improve learning or performance.

- Students can study "smarter": Not only is there a wide range of studying strategies available to students but some strategies have been found to be more/less effective (for individuals or for particular types of learning or course content). We can help students become aware of varied ways to approach materials we are teaching in our courses. As [18] Pintrich (2002) reminds us, it is not surprising that students who are aware of varied strategies for studying and learning in different contexts and for different tasks are more likely to employ these strategies.

- Students who focus on planning and managing their time can increase their efficiency/productivity.

- Although it is important to take notes in class (handwritten has been found to prove better for learning), relying on one's own notes exclusively can be problematic; their own notes may misrepresent or even entirely miss important information.

- We can do more to encourage students to take advantage of any additional resources offered through a class (such as a review session by a TA or a study 
guide offered by the instructor) as well as through the university at large (e.g. Academic Tutoring Center, Writing Center, Math Center, and more).

- We can work to foster "growth" mindsets allowing to see that abilities aren't so much something with are born with as something we can improve.

In subsequent analyses of students' reflective writings, we will focus on such aspects as how students defined success in the course, how they expected to perform on upcoming exams, their levels of confidence as learners, and the extent to which they seemed to have a growth mindset ("I can learn and improve") or a fixed mindset ("I'm not good at math and never will be). We expect as well to connect what we learn from student reflections to their performance in the class. Although so far we haven't identified connections between growth in the metacognition awareness to actual improvements in grades, we believe that we as instructors can be more explicit about sharing promising approaches to learning and thinking about how best to learn in engineering and beyond. Students' reflective journals allowed us to see that minimally addressing "thinking about thinking" or "learning to learn" can help expand students' approaches to learning if not knowing when to apply a given approach as opposed to others--all putting learning more squarely into the hands of the learners themselves [19].

\section{References}

[1] A. Gibson, K. Kitto, and P. Bruza (2016). "Towards the discovery of learner metacognition from reflective writing." Journal of Learning Analytics, 3(2), pp. 22-36.

[2] J. H. Flavell (1976). "Metacognitive aspects of problem solving.” In L. B. Resnick (Ed.), The nature of intelligence (pp. 231-236). Hillsdale, NJ: Erlbaum.

[3] M. Hora and A. Oleson (2017). "Examining study habits in undergraduate STEM courses from a situative perspective.” International Journal of STEM Education, 4(1), pp. 1-19.

[4] S. Hug, E. Villa, P. Golding, and G. Gandara (2015). "Learning to learn: Creating engineering classrooms for deep understanding." Frontiers in Education Conference (FIE), 2015. IEEE, pp. 1-5.

[5] I. Boutet, M.-P. Vandette, and S.-C. Valiquette-Tessier (2017). "Evaluating the implementation and effectiveness of reflection writing." The Canadian Journal for the Scholarship of Teaching and Learning 8(1), Article 8. http://ir.lib.uwo.ca/cjsotl_rcacea/vol8/iss1/8

[6] S.B. Shum, Á. Sándor, R. Goldsmith, R. Bass, M. McWilliams (2017). "Towards reflective writing analytics: Rationale, methodology, and preliminary results." Journal of Learning Analytics, 4(1), 58-84. http://dx.doi.org/10.18608/jla.2017.41.5.

[7] Ryan, M. (2011). "Improving reflective writing in higher education: A social semiotic perspective." Teaching in Higher Education, 16(1), pp. 99-111. http://dx.doi.org/10.1080/13562517.2010.507311 
[8] M. Credé and N. R. Kuncel (2008). "Study habits, skills, and attitudes: The third pillar supporting collegiate performance.” Perspectives on Psychological Science, 3(6). 425453.

[9] G. Schraw and R.S. Dennison (1994). "Assessing metacognitive awareness.” Contemporary Educational Psychology 19(4), pp. 460-475

https://doi.org/10.1006/ceps.1994.1033

[10] K. D. Tanner, K.D. (2017). "Promoting student metacognition." CBE_Life Sciences Education 11, (2), pp. 113-120. https://doi.org/10.1187/cbe.12-03-0033

[11] S.Y. McGuire (2015). Teach Students How to Learn: Strategies You Can Incorporate Into Any Course to Improve Student Metacognition, Study Skills, and Motivation. Sterling, VA: Stylus Publishing.

[12] National Survey of Student Engagement (2011). Fostering Student Engagement Campuswide-Annual Results 2011. Bloomington, IN: Indiana University Center for Postsecondary Research.

[13] J. Dunlosky, K.A. Rawson, E.J. Marsh, M.J. Nathan, and D.T. Willingham (2013). "Improving students' learning techniques: Promising directions from cognitive and educational psychology." Psychological Science in the Public Interest 14(1). 4-58.

[14] K. Carlson, D. Turvold Celotta, E. Curran, M. Marcus, and M. Loe. (2016).“Assessing the impact of a multi-disciplinary peer-led-team learning program on undergraduate STEM education." Journal of University Teaching \& Learning Practice, 13(1), pp. 1-21. Available at: http://ro.uow.edu.au/jutlp/vol13/iss1/5

[15] F. Boch and A. Piolat (2005). "Note taking and learning: A summary of research. The WAC Journal, 16, pp. 101-113.

[16] M.C. Everett (2013). "Reflective journal writing and the first-year experience. International Journal of Teaching and Learning in Higher Education 25(2), pp. 213-222.

[17] A. Siegesmund. (2016). "Increasing student metacognition and learning through classroombased learning communities and self-assessment. Journal of Microbiology \& Biology Education, 17(2), pp. 204-214.

[18] P.R. Pintrich (2002). "The role of metacognitive knowledge in learning, teaching, and assessing." Theory into Practice, 41(4), pp. 219-225.

[19] B.J. Zimmerman (2002). "Becoming a self-regulated learner: An overview." Theory into Practice, 41(2), pp. 64-70. http://dx.doi.org/10.1207/s15430421tip4102_2 